\title{
Furthering Inclusive Education through Full-Service Schools: A Workable Strategy?
}

\section{Jacomina Motitswe}

\author{
Department of Inclusive Education, University of South Africa (UNISA), PO Box 392 Pretoria 0003 \\ motitjmc@unisa.ac.za
}

\section{Doi:10.5901/mjss.2014.v5n8p415}

\section{Abstract}

\begin{abstract}
The South African government introduced Full-service schools for the implementation of inclusive education at practical level and to chart the way for all schools/ institutions to ultimately become inclusive institutions. The aim of this study is to explore the implementation of inclusive education in a Full-service school on addressing diversity and the management of inclusive classrooms. Full-service schools provide quality education to all learners through flexibility, and meeting the full range of learning needs in an equitable manner and are institutions that strive to transform themselves, proactively addressing the barriers to learning and increasing participation of the learners and educators. They strive to achieve success, equity, quality and social justice in education (DoE, 2002: 4). Qualitative research and purposive sampling was used in this research. The triangulation of data collection using three data collection instruments which are focus group interview, document analysis and observations were used to enhance and enlighten aspects that may be obscured by one method. Full service school teachers formed the core focus of the participants. This study was informed by asset-based theory,., Vygotsky's theory of proximal development (ZDP) and Bronfenbrenner's ecological theory. The findings of the study indicate that the diverse learning needs were addressed; teachers used curriculum differentiation to accommodate all learners in their classrooms.
\end{abstract}

Keywords: Inclusive Education; Barriers to learning; Full Service School. Diversity, Curriculum differentiation

\section{Introduction}

The implementation of inclusive education has dominated the debates in education around the world since the World Conference on Special Needs Education which was held in Salamanca, Spain in 1994 (UNESCO, 1994), and different opinions have evolved on how best to make schools more inclusive to accommodate all learners who experience barriers to learning and development. In keeping up with the trends in inclusive education worldwide, the South African Department of Education (DoE) has introduced the Education White Paper 6 on Special Needs Education: Building an Inclusive Education and Training system, 2001, which is a legislative and policy framework that addresses the building of a single, inclusive system of education that is based on the principles of social justice for all learners, human rights, a healthy environment, participation, social integration and redress, equal and equitable access to education, community responsive and cost effectiveness (DoE, 2001). Inclusive education is defined as a dynamic process of addressing and responding to the diversity of needs of all learners by reducing barriers to and within the learning environment, and of seeing individual differences not a problems but as opportunities for enriching learning (DoE, 2001).

The Education White Paper 6 (DoE, 2001) introduced full-service schools to underline the important role mainstream schools play in developing inclusive systems. The Department of Education regards full-service schools as mainstream education institutions that would provide quality education to all learners by supplying the full range of learning needs (DoE, 2009). They would strive to achieve access, equity, quality and social justice in education, and promote a sense of belonging so that all learners and educators experience a sense of worth in the learning community. Full-service schools are schools that have the capacity to respond to diversity by providing appropriate education for the individual needs of all learners, irrespective of disability or differences in learning styles, pace or social difficulties experienced (DoE, 2009).

Although much research has been done on the attitudes of educators towards the implementation of inclusive education, determinedly, none has been done to explore how full-service schools are furthering the implementation of inclusive education. Therefore the research that is described in this article focused on this important aspect. The aim of this research was to report on how a full-service school implemented inclusive education. There are many factors that may influence the implementation of inclusive education, but this research focused on the following: addressing diversity in the classroom, managing inclusive classrooms and support to the school, learners, Institute level support team.

The theoretical framework, a literature review on this topic as well as the research methodology and findings are 
discussed. Recommendations are made based on the conclusions that were drawn.

\section{Literature Review}

A review of literature on inclusive education reveals that the philosophy of inclusion in the South African Education system is rooted in the country's Constitution (South Africa, 1996a), which itself is grounded in the values of human dignity, the achievement of equality and the advancement of human rights and freedom (South African Schools Act $\{S A S A\}, 1996 b)$. For that reason, the move towards inclusion in the country's education system has aimed at maximizing the participation of all learners in education and developing them to become fully functioning citizens who can participate meaningfully in the country's economy, and be able to compete globally. According to the Salamanca Statement (UNESCO, 1994), inclusion was the guiding principle that schools should accommodate all learners regardless of their physical, intellectual, social, emotional, linguistic or other conditions. It was agreed by Sapon-Shevin (2007) that inclusion begins with the right of every child to be in the mainstream of education. This should include learners with disabilities and gifted learners, as well as street and working learners.

The department of education (DoE, 2001) pointed out that an imperative point of departure to engage in the process of inclusion was to convert ordinary schools into full-service schools. These are mainstream schools that are specially equipped to address a full range of barriers to learning in an inclusive education setting. In addition to their ordinary learner population they will become accessible to most learners in an area for those who experience mild to moderate barriers to learning and provide the necessary support. In the initial implementation stages these full service will be models of institutional change that reflect effective inclusive cultures, policies and practices (DoE, 2005b). To understand the Department of Education's viewpoint it is necessary to give a background of the development of fullservice schools

\subsection{The development of full-service schools}

One of the first strategies to introduce the policy of inclusive education in South Africa was to convert a number of ordinary schools to full-service schools. South Africa is divided into nine provinces, and each province is divided into different districts. In 2004, the Department of Education did a field test that was conducted in 30 selected districts from the nine provinces targeting 30 selected full-service schools (DoE, 2009). These were primarily mainstream schools that would provide quality education to all learners by supplying the full range of learning needs in an equitable manner, whilst striving to achieve access, equity, quality and social justice in education (DoE, 2001). From a later publication, the department of education (DoE, 2005) stated the aim of full-service schools as being to allow everyone to learn and participate fully. All development and work in the schools would strive to achieve these goals by sharing expertise and constantly thinking about the development of both educators and learners. Full-service schools would be prepared to explore and address the challenges of everyday school life through capacity building among educators and on-going institutional development aimed at transforming the whole school. The department of education (DoE, 2005) also envisaged full-service schools as being a beacon of the transformation process in education by developing cultures, policies and practices that embrace diversity, respect difference and value innovation and problem-solving. They would create a safe and supportive environment in which educators would be motivated and supported in their work, where learners would feel a sense of belonging and be able to engage in the learning process, and where caregivers would be valued and involved in the life of the school community.

Policies and guidelines on inclusive education may be good and progressive in theory, but in practice there are many gaps that may hamper the implementation such as poverty and unemployment rate in areas; a high rate of HIVIAIDS; the illiteracy of parents; many different home languages; inadequately trained educators with regard to learning support; learners who experience intrinsic barriers such as learning difficulties; attention and hyperactivity difficulties; visual and hearing impairments, and down's syndrome.

\section{Theoretical Frameworks}

The asset based theory and Vygostky's theory of Zone of Proximal Development (ZDP) (1978) formed the underlying structure of the research. The manner in which the classroom environment is being experienced, that is activities, interactions and relationships between learners and how the teachers view classroom environment such as resource materials, organisation, design, teaching methodology and the number of learners in a class, in relation to the implementation of inclusive education is theorised within the asset- based paradigm. The classroom is conceived as the 
social context for learning, where learners acquire knowledge and skills through interaction with capable others (peers and teachers). The environment within a classroom must stimulate communication between learners and teachers. This involves the organisation of seating patterns and relations where learners are able to communicate freely with each other and value norms of co-operative learning in which competition is discouraged. In relation to the aim of the research, the classrooms arrangement accommodated all the learners including those who were using wheelchairs because there were ramps all over the school building to allow them to enter the classrooms and there was enough space in the classrooms for them to seat and move around during group work and to access the resource materials.

Every learner in this context should feel accepted and part of the group, and be motivated to contribute to learning. This will in turn facilitate learning as a social action and enable learners to take responsibility for their own learning (Gagnon \& Collay, 2006).

Vygotsky's theory of the Zone of Proximal Development (ZPD) (Vygotsky, 1978) provides the framework for effective inclusive teaching and learning in the classroom. According to this theory, learning is a path through the ZPD, with the term 'zone' referring to the space between which a learner cannot do alone and that which he or she can do with the help of capable others, such as peers or educators (Pettigrew \& Akhurst, 1999). In other words, the learner will be moving from the known to the unknown with the help of the capable others in his or her environment. From this, Rowlands (2006) argues that teaching happens most effectively when assistance is offered at those particular points in the ZPD where the learner requires help, and there is a distinction between what the learners have mastered and where they are in the process of learning.

\section{Research Methodology}

The study used a qualitative research approach because it was based on collaborative human activities looking at how diversity is addressed in order to meet the learning needs of all learners in inclusive classrooms. To enhance a valid understanding of inclusivity the organisation and management of the classroom in order to accommodate all the learners, were also studied. Furthermore the support services to address barriers to learning were also focused upon. According to Creswell (2003) qualitative researchers deals with socially constructed realities and qualities that are complex and indivisible into discrete variables. A case study was used to explore the implementation of inclusive education at a fullservice school. According to Cohen, Manion and Morrison (2007) the strength of a case study design is that its effects are observed in a real context, recognising that this is a powerful determinant of both cause and effect. Inclusive classrooms at a full-service school as the context in which teaching and learning occur were explored, investigating how diversity is addressed to accommodate all learners and to explore if the classroom environment were inclusive and whether the curriculum was adapted and modified to accommodate all the learners.

Purposive sampling was used as it is based on the assumption that the researcher wants to discover, understand, and gain insight, and therefore must select a sample from which the most can be learnt (Merriam, 2002). The scope of the research was limited to a full-service school in the North West Province in Bojanala Region at Moses Kotane East Area Project office (APO) in South Africa. The Foundation Phase, grade one, two and three were used because of the researcher's experience and understanding of the phase, and because it is regarded as the critical phase for developing the learner holistically and early identification and addressing barriers to learning as well as promoting an interest in education. All the six Foundation Phase teachers including the head of the department participated in the study. Focus group interviews, observations and document analysis were used to collect data.

According to Neuman (2011), ethical issues are the concerns, dilemmas and conflicts that arise over the proper way to conduct research. Ethics define what is or is not legitimate to do, or what moral procedure is involved. Taking cognisance of this indispensable requirement, the research was undertaken in accordance with the prescribed ethical principles of social legal research in terms of permission from and access to the institution, and acceptance by relevant education authorities, participants' informed consent, privacy, confidentiality and freedom from deception or betrayal.

These various data collection methods were not only necessary to get balanced research results but they also brought interesting viewpoints and findings which will now be discussed

\section{Results and Discussions}

As the focus of this research was on addressing diversity in inclusive classrooms and support to the learners, teachers and the school, the findings on these various topics will now be discussed. 


\title{
5.1 Addressing diversity to accommodate all the learners at a full-service school
}

Responding to the question on addressing diverse learning needs, the participants indicated that there are learners from different backgrounds such as socio-economic background, who live in poverty and extended families depending on their grandparents grants, learners affected and infected by HIVIAIDS; cultural, ethnic and ability groups, disabilities such as intellectual disabilities, learners who are using wheelchairs and learners with cerebral palsy, hard of hearing, short sighted. The other extrinsic barriers that the participants mentioned are the inflexible curriculum, language and communication, lack of parental support and involvement. The following are verbatim quotation from the focus group interviews:

\begin{abstract}
The most barriers that we experience, especially in Grade One classes, is the language barrier. These cause communication breakdown because most learners are speaking IsiZulu, IsiXhosa and Xitsonga. And you find that I, as the educator cannot talk the learner's language, especially Xitsonga.

Most of the learners are staying with their grandparents; other parents are not educated and are unable to assist their children with their home work. There is no parental involvement. The parents are not involved in their children's education........ and that makes intervention to be difficult for us, because every time the parent is called, he or she does not respond

The other barriers that we experience, Mam, is socio-economic, poverty at home, the situation that they are facing at their homes; Poverty is also the dominant problem in our school. Most learners depend on their grandparents' pension grants. We also have orphans who are not well cared of; Due to this poverty; most of the learners come to school being very tired and hungry and most of the children are not provided with basic needs.

We do have learners with physical disabilities such as those who use wheelchairs, those who are hard of hearing, short sighted and who have cerebral palsy.
\end{abstract}

The discussions are mentioned in the next paragraphs to explain how barriers were addressed to accommodate all the learners.

\subsection{Language and communication}

As a multicultural nation, learners find themselves in classrooms where the language of learning and teaching is not the home language for all the learners. This results in language and communication barriers because some learners cannot understand the curriculum. Responding to the question on language and communication, the participants indicated that their learners are from different cultural groups such as Xhosa, Zulu, Xitsonga, Northern Sotho and Tswana. They indicated that the language of learning and teaching in the Foundation Phase is Setswana and that caused communication breakdown especially in Grade One.

All the participants who took part in the focus group indicated that they address the language barrier by code switching between Setswana, Isizulu and English and also using pictures and concrete objects to explain what they are teaching so that the learners can understand better. They also indicated and the researcher observed that they use older learners who speak the same language to explain to the others what is being said, which relates to Vygotsky's theory of the Zone of Proximal Development that a learner can do better with the help of capable others, such as peers or educators. This also means that the teachers use all the resources they have to support every learner in their classrooms. The participants mentioned that during oral time they allow learners to tell their stories in their own home language and the other learner who speaks or knows the language to explain the story to the whole class afterwards. It was observed and also confirmed during the interview that the teachers label all the objects in the classrooms in both Setswana and English and explain them in the learners' home language.

As noted that the language of learning and teaching (LOLT) is one of the barriers to learning, the findings reveal that code switching is seen as a way of addressing it. This affirms what the department of education (DoE, 2005b) raised that when a learner enters school in which the language of learning and teaching (LOLT) is not their home language, the educators of all language programmes or learning areas in the school should provide support and supplementary learning in the LOLT until such time that the learners are able to learn effectively through that particular language.

From the findings it was apparent that the LOLT, which is Setswana, was one of the barriers to learning because most learners come from different cultural backgrounds. This means that the common barriers associated with language and communication are related to forcing learners to communicate and learn in a language which they do not usually use at home and are not competent to learn. The researcher argues that young learners learn a second language easily, even though the depth of knowledge of the other language may differ to the other one. 
The following paragraph will explain how other contents of the curriculum are addressed to accommodate all the learners learning needs.

\subsection{Addressing diversity through the curriculum}

The participants indicated that they respond to the diverse learning needs of all learners by modifying, adapting and varying their teaching methods, teaching strategies and the learning content. This is in line with what UNESCO (2005) explained an inclusive classroom, that teachers need to make sure that the curriculum is accessible and relevant to all learners in terms of what is taught (content), how the educator teach it, how the learner learn best and how it relates to the environment in which the learners are living and learning.

The participants spoke at length about differentiated lesson planning, differentiating teaching methods and differentiating the learning environment to accommodate all the learners in the classrooms, especially those who experience barriers to learning. They explained that the differentiated lesson plans indicate the different activities that are done by different learners in the classrooms. According to the observation and the focus group interviews, the participants still follow the milestones as set out by the Foundations for Learning for all the Learning Programmes but they implement them inclusively to accommodate all the learners.

The teachers mentioned that the learners' level of ability was considered. They indicated that they place learners in groups and each group is given its own activities that suit their level of ability. According to what was observed, the participants introduced a target concept to the whole class first, using story telling or songs and rhymes. Throughout the presentation of the concept during the lesson, the teachers then simplified the instructions to accommodate all the level of abilities and to arouse the learners' interest. The activities were differentiated according to their level of ability, interest and proficiency of language skills.

The participants mentioned a lot about straddling of assessment standards and activities to provide learners who experience barriers to learning with activities that suit their level of abilities. They mentioned that those learners are provided with alternative assessment, but that providing learners with alternative assessment was done for intervention process to support them.

\subsection{Diversity and various teaching methods}

The participants indicated that in order to respond and accommodate the diverse learning needs, they differentiated the teaching methods and strategies. They also indicated that using differentiated methods means that they consider the resources, methods of presentation and activities. They identified different methods that they are using to teach in inclusive classrooms such as storytelling using puppets and big books; songs and rhymes; dramatisation; games; cooperative learning in solving problems and in making projects; group work and individual work. It has been observed and also mentioned during the focus group interview that they used colourful pictures, facial expression, and gestures and also varied their tone of voice in order to arouse the learners' interest and to help learners understand. They also used posters of different concepts such as healthy living; money; transport, people at work, my school and others. The following are the verbatim quotations from the focus group interview with the Foundation Phase educators:

\footnotetext{
We use different types of methods. We use multi-level teaching because learners vary according to their level of ability. We also use storytelling, whereby an educator tells a story, using pictures and a big book for that matter, and we also allow the learners to retell the story and also dramatise it"; Some learners learn best through songs; others like rhymes; and others can understand and cope by listening while the educator is teaching; Some can even formulate a game from an activity, especially in numeracy, when they count. The learners grasp a lot as they play.
}

It was observed that when giving learners activities, the teachers explained the instructions to the whole class and to each group first and later walk around the groups to provide assistance to those learners who experience barriers to learning. Some learners were taught on a one- to- one basis, which is individualised teaching.

\subsection{Classroom organisation and management in Foundation phase classrooms}

The class sizes ranged between 35 and 45 in each Grade. The teachers used the number of learners in their classrooms to create seating arrangement that will be conducive to teaching and learning in terms of accessing the resources and free movement during group work. They explained that they usually consider the learners who experience physical 
disabilities when making seating arrangement. They allowed learners who are using wheelchairs to sit comfortably and can access the resources. The teachers explained that learners who have got short eye sight are seated in front where they could see the chalkboard clearly and the light is controlled so that it should not disrupt their eye sight. Learners who are hard of hearing were seated where they could see the teachers' face, lips and gestures when speaking.

The seating arrangement was conducive to teaching and learning, with sufficient space for free movement during group activities, and also for both the learners and educators to access the resources easily. Learners were seated in groups of six

Our classrooms are spacious enough to accommodate even wheelchairs. In some classrooms there are learners, who are using wheelchairs and they feel at home; the advantage with our classrooms is that they are not overcrowded

According to the Guidelines for full-service schools (DoE, 2010), it states that one learner who experience barriers to learning, either being physically or intellectually, that learner equals two learners who do not have barriers. That means if there are four children who experience barriers to learning in one classroom, and the total number of all the learners is forty, and then the actual total number would be forty-eight learners which contradict with the learner-teacher ratio of 1 : 35. The Guidelines for full-service schools (DoE, 2010) states that if a full-service school has an enrolment of more than 500 learners, it qualifies for a full time learner support educator who will assist class educators in case of learners who need special attention. This is not practically implemented which put teachers under stressful situations of facing those number of learners who experience barriers to learning on their own in classrooms.

\subsection{Support at school}

In responding to the issue of support, the teachers indicated that there is collaborative network of support for all the educators within the school. They indicated that teachers work as a team and learn from each other; develop learning materials together per phase. They explained that their school serve as a resource centre for other neighbouring schools and also formed an inter -sectoral collaborative committee which consisted of representatives from heath, social welfare, police, tribal authority, students from North West University at Mankwe Campus, Child Protection Unit and Home affairs.

All the teachers were very positive about the support they receive from the school management team and the Institute level support team (ILST). They mentioned that the school management team with the support from the school governing body make every effort to request donations and sponsorship from different sectors. The data that was gathered through document analysis as well as focus group interview revealed that the school received sponsorship from Teba bank, Sun City hotel, Airport Company South Africa (Pilanesburg international airport) such as funds for refurbishment of school building to make ramps for learners who are using wheelchairs, furniture that was accessible for learners with physical disability, wheelchairs, school uniform and paying school funds for learners who are from low socio economic backgrounds and funds for sustaining the vegetable garden. The teachers indicated that the school management team always buy all the necessary resources necessary for teaching and learning that are inclusive in nature. The researcher wanted further clarity of resources that are inclusive and the educators gave examples of learners who have cerebral palsy, that they are provided with stationary such as carpenter pencils, books with larger lined areas and they are given extra time to complete their activities.

The findings reveal that those learners who come from low socio economic background receive support on basic needs such as school uniform from donors, learning materials and something to eat at school, which motivate them to attend school and might also reduce absenteeism.

\subsection{Support from the Institutional level support team}

From the focus group interview with the institutional level support team to get more information about their support to the teachers and learners, their duties and responsibility were clearly outlined and they also confirmed that they support the teachers in identifying and addressing barriers to learning and developing a support programme for those learners who experience barriers to learning. They indicated that they usually meet once per term with all the educators to discuss the intervention programme and how the teachers should do the intervention programme in their classrooms and how to support learners who experience barriers to learning in all the learning areas. The members indicated that if there is no progress during intervention then the educators refer those learners to the ILST to intervene and they develop Individualised Education Plan (IEP) for those learners to provide individual support to them. The ILST indicated that they liaise with the District based support team (DBST) in terms of severe cases and they work cooperative with them to refer 
the learners who have severe barriers to learning to the relevant institution. The members indicated that they get a lot of support from the District based support team.

Yes, we do receive a lot of support from the DBST. And I think it is because of the efforts we took as a school. For this school to be selected as a full-service school is because we were networking with the DBST so that they could assist us with the problems we encountered at school. The DBST arrange workshops for us, like the latest one we attended on SIAS, which is Screening, Identification, Assessment and Support

Yes we were trained on how we should screen and identify learners with barriers to learning and how to assess them. The DBST also assist us in year plans and also on looking for sponsors for the school. They assisted us to get sponsorship of wheelchairs. They are always available for us if we need assistance

The institute level support team confirmed the support they received from the district based support team and it was also confirmed by the documents that were analysed, which indicated gaps in terms of screening, identification, assessment and support (SIAS) because the comments made by the DBST during monitoring at the school indicated that there were some missing support documents as evidence that the teachers were implementing what they are supposed to. When the researcher asked about the comments, the ILST mentioned that they did not understand the strategy on SIAS and still need workshop on identifying and addressing barriers to learning.

We did attend the workshop on SIAS but we still have problems of not understanding other aspects on identifying and addressing barriers to learning.

I think it will be best and advantageous for the school to further our studies and specialise on inclusive education, which should be financed by the department of education as a professional development for educators working in full-service schools.

The findings reveal that the teachers where the research was done are dedicated, determined, committed; they compromise and improvise to accommodate all learners in their classrooms. This was supported by the fact that they got more support from the DBST because of the efforts they take in implementing inclusive education. The gaps in terms of curriculum, screening, identification, assessment and insufficient knowledge on educators and ILST were also revealed.

\section{Conclusion and Recommendations}

The findings confirm the department of education (DoE, 2005b) statement that there is no single classroom in which all learners are exactly the same, or learn in the same way or at the same pace; as a result, educators are required to be creative in using a variety of teaching methods to reach all the learners.

However, during the research there was absence of support strategies which were outlined in the policies to ensure successful implementation of inclusive education. The other example as mentioned in the Guidelines for fullservice schools (DoE, 2010), is that a full service school having an enrolment of 500 learners are entitled to a full time learner support educator. Full-service schools should also use differentiated curricula to accommodate all learners including those who experience barriers to learning. It is also important that alternative and adaptive assessment should be provided to these learners.

According to the researcher's view, alternative assessment does not relate to the annual national assessment (ANA) in the sense that the the former is set by the teachers based on the learners level of abilities and differences, whereas the annual national assessment is set by the Department of Education without considering learners who experience barriers to learning, the tasks are supposed to be written by all learners per grade. This contradicts to what the Guidelines for full-service schools (DoE, 2010) explain about giving those learners who experience barriers to learning alternative and adaptive assessments, unless if the school does not understand the policy on ANA to accommodate and support learners who experience barriers to learning.

Even though teachers expressed confidently that they use curriculum differentiation and differentiated teaching strategies, the findings indicated that not all learners were supported and the activities they were given did not suit their level of abilities.

Teachers are trying to implement inclusive education, but they still lack knowledge and skills on screening, identifying, assessing and supporting learners who experience barriers to learning, curriculum differentiation and managing the inclusive classrooms.

It is therefore recommended that differentiated teaching, lesson planning and assessment should be provided continuously, not only for intervention purposes. The formal assessment tasks, including the annual national assessment 
set by the DoE, should also accommodate learners who experience barriers to learning, that is, alternative tasks should be provided for those learners as their formal tasks. There should be strong and active collaboration between the school, parents, stakeholders and NGOs. Full-service schools should be provided with learner support teachers or assistant teachers, without considering the number of learners in a school, because there are cases that need special attention for learners who experience barriers to learning. Full-service schools should have their own norms and standards so that teaching and learning can be effective and accommodate diversity. Parents should be made aware that their services are very important in the education of their children; this can be done by encouraging them to volunteer to teach skills and values, such as telling stories from a different cultural background; telling stories about different special ceremonial practices, and teaching learners about different traditional food, songs and dance. This will motivate other parents to be involved in their children's education. The school should also organize and provide training and workshops to parents on addressing barriers to learning and support their children.

\section{Reference}

Cohen, L.; Manion, L. \& Morrison, K. (2007). Research methods in education. New York: Routledge.

Creswell, J.W. 2003. Research design: Qualitative and quantitative Approaches. California: Sage.

Department of Education. (2001). Education White Paper 6: Special needs Education. Building an Inclusive Education and Training System. Pretoria: Government Printer.

Department of Education. (2005b) Conceptual and operational guidelines for the implementation of inclusive education: Full-service schools. Pretoria: Government Printer.

Department of Education. (2009) Department of Basic Education. Guidelines for Full- service/ inclusive schools. Pretoria: Government Printer

Department of Education. (2010) Department of Education. Guidelines for Full-service/ Inclusive schools. Pretoria: Government Printer.

Landsberg, E, Kruger, D, Nel, E (2005). (Eds). Addressing barriers to learning. Pretoria: Van Schaik.

Merriam, S.B. (2002). Qualitative research and case study applications in education. California: Jossey- Bass.

Neuman, W.L. (2011). Social research methods. Qualitative and quantitative approaches. $5^{\text {th }}$ edition. Boston. Allyn and Bacon.

Pettigrew, L. \& Arkhust, J. (1999). Learning and Teaching: Psychological Perspectives. Pietermaritzburg: School of education, Training and Development, University of Natal: Pietermaritzburg.

Rowlands, T. (2006). The Impact of Using the Scaffolded Literacy Strategies as Developed by Dr. David Rose in South African Special Needs Context. University Of KwaZulu-Natal: Pietermaritzburg.

South Africa. (1996b). South African Schools Act 84 of 1996. Pretoria: Government Printer.

Swart, R.E.; Pettipher, O.R.; Engelbrecht, P.; Eloff, I.; Oswald, M.; Ackerman, C.J. \& Prozesky, A.M. Teachers' attitudes towards and experiences in implementing inclusive education. Paper presented at the EASA Conference in Bloemfontein, January 19-21, 2000.

UNESCO. 1994. The Salamanca Statement and Framework for Action on Special Needs Education. Paris: UNESCO.

UNESCO. 2005. Understanding and Responding to Children's Needs in Inclusive Classrooms: A Guide for the Teachers. Paris: UNESCO.

Vygotsky, L.S 978). Mind in society. Cambridge: Harvard University Press. 